\title{
A Study on the Behavior of Change \& Korean Dance Creation by Foreign Visitors
}

\author{
Ji Young Yoo ${ }^{1}$, Yeon Soo Kim ${ }^{2, *}$ \\ ${ }^{1}$ Institute of Sport Science, Korea National Sport University, No.1239, Yangjae-daero, Songpa-gu, Seoul, Republic of Korea \\ ${ }^{2}$ Department of Road and Geomatics at Civil Engineering College, National University of Engineering, No Av. Tupac Amaru \\ 210, Lima, Peru
}

Received September 10, 2020; Revised January 19, 2021; Accepted January 28, 2021

\section{Cite This Paper in the following Citation Styles}

(a): [1] Ji Young Yoo, Yeon Soo Kim , "A Study on the Behavior of Change \& Korean Dance Creation by Foreign Visitors," International Journal of Human Movement and Sports Sciences, Vol. 9, No. 1, pp. 140 - 148, 2021. DOI: 10.13189/saj.2021.090120.

(b): Ji Young Yoo, Yeon Soo Kim (2021). A Study on the Behavior of Change \& Korean Dance Creation by Foreign Visitors. International Journal of Human Movement and Sports Sciences, 9(1), 140 - 148. DOI: 10.13189/saj.2021.090120.

Copyright $\bigcirc 2021$ by authors, all rights reserved. Authors agree that this article remains permanently open access under the terms of the Creative Commons Attribution License 4.0 International License

\begin{abstract}
In general, each of the aggregates is favored as not being a carrier. Foreign visitors were applied, information responsive, and visit experience. The reason was, the intimacy of behavior change and behavior change of attitude later became an opportunity to create Korean dance. In this study, 268 foreign visitors were examined to derive the creation and behavior of Korean dance. We investigated the behavioral change and its impact on the creation of Korean dance. It was supported by factor variables: intimacy, attitude, behavior change, and Korean dance creation. These results are probable as content factors of knowledge as manipulated variables estimated to increase. It applied the tools of the methodology to frequency analysis, factor analysis and regression analysis in social science with statistical use. Independent variables are intimacy, attitudes, and behavioral changes. The intervening variables are foreigner's visit experience, information acquisition. The dependent variables are behavior of change and Korean dance creation. As a result, there was a significant impact on visitor intimacy, attitude, nationality and behavioral change, which positively affected 67.8 (\%) behavioral change. In addition, the creation of Korean dance was influenced by the result of behavioral change, intimacy, attitude, and visit experience and information acquisition, and 77.9 (\%) very high result in behavioral change and creation of Korean dance. However, there was insufficient impact significant effect on performance viewing and time $9.8(\%)$. When the results of the study are concluded, the factor contributing
\end{abstract}

to the creative development of Korean dance has an indirect effect where there is a behavior of change by foreign visitors. It was found that it had an indirect effect on the new of Korean dance creation.

Keywords Intimacy, Attitude, Visiting Experience, Korean Dance Creation

\section{Introduction}

Korean dance is a national art. Korean dance has a history, culture, and lifestyle. Korean dance originated from ancient times and was protected and worshiped. It is meant to prevent diseases, disasters, and was thought to bring abundance into the traditions of long ago. It was understood from having the form of the state, it was expressed "dance" and "music". In addition, experts have been nurtured by state agencies since coming to modern times. During the Joseon Dynasty, it developed into a folk dance by the royal family. Korean dance was an art. Depending on the means, purpose, function, and location, the degree of completeness has been improved. Along with this, the Korean dance began to decline, and it was the cause of the Japanese invasion, the Korean War, and the pain in history. It develops as Western culture enters. Together, new dance and Korean traditional dance. From 
this point on, it becomes the basis of re-development in the name of Korean dance creation. As modern dance, Korean dance develops and promotes. By being refined, Korean culture develops with intimacy in the world. Today's K-Pop status has a Korean dance origin. Therefore, this study comparatively studied behavioural change for foreigners according to the perspective of each country from the empirical aspect of whether it changed according to the familiarity of Korean dance and the intimacy and attitude of viewers.

\subsection{Necessity}

The need for this study is that the concept of Korean dance is rational objectivity to enhance it. 1) The spirit of the present and future. 2) I see it as a religious special situation, and the reason exists, as funeral dances, Buddhist dances, and shamanic dances. 3) Distinguish between good and evil for humans, it sublimates into Korean dance. It is expressed in Korean dance and prevents evil. It is expressed in Korean dance. The origin of happiness. 4) Pursue the spirit of conversion to Korean dance. Sorrow is transformed while pursuing a change in the spirit of joy. 5) Korean dance is a unit of consciousness. Korean dance is a ritual that transforms sadness into joy by happily changing the aesthetic sense. 6) Korean dance is interpreted as the joy of life. 7) Korean dance has a community spirit, it is a village community, a labor community, and a pursuit of community consciousness rather than individual happiness. 8) Korean dance has a spirit of morality and courtesy [1]. Korean dance is the spirit of the Korean people, and Korean dance was created, so that society is transformed. It means the process of change of behavior, which can be explained extinction, soil, development, and the process of change. The intimacy and attitude of Korean dance to foreigners increases the likelihood of changes in the behavior of Korean dance.

Our aim is to go deeper into this topic, Study analysis of differences in intimacy, attitudes and behavior of change those who are not, by foreign visitors. In this study, we analyzed how differences affect behavior of changes and K-pop production. The ultimate goal is to provide, contribute, and promote foreign visitors' experience paths, also social mediation, and useful information and encouragement of Korean dance. The global K-pop group is creating change, and through action change, it is being driven by the reaction of people around the world through the fusion of Korean traditional dance and K-pop dance [2]. This study attempted to find out, if possible, to teach, Korean traditional dance based on preferences and experiences of Korean dance for foreign visitors. Based on the research results, the curriculum of Korean dance has been developed, and theoretical growth and reflection in the sociological dimension. Therefore, the curriculum complementation of Korean dance and the interdisciplinary relationship.

\section{Theory of Background}

\subsection{Description of the Theory}

Behavior it can be grounded theory since being a member of the community is a reflection of the process of understanding the object of action. In this process, the subject and object are said to be the same. According to Willock, etc. [3], the life world that appears in this way is seen as an objective knowledge to understand social phenomena, and the value of the social phenomenon starts from individual objects. As well as inter-subjectivity in the life world includes the meaning of accumulated time [4]. Therefore, mutual subjectivity has a theoretical implication that can explain it [5]. The study has the possibility of the methodology in the process of forming the knowledge system [6]. Therefore, we intend to utilize this study. The methodology of interdependent subjectivity in the life world of phenomenology Moreover, it could be utilized as a new variable of the methodology. Interrogation process, consciousness flow, and experience and time to objectify more than mutual subjectivity [7].

The researcher's theoretical background was based on limits to the extent of factual visits and information acquisition by foreigners on behavior change. Researched for the basics visiting experiences, information acquis ion about visit opportunities and behavior of change and Korean dance creation. On the basis of the search was described. Exploration visitor's experiences, and visitor's information pathways behavior of change and Korean dance creation. With sufficient real control over behavior of change, foreign visitors' intentions are inferred when opportunities arise. Therefore, the limitation of the range of recognizing and acting will be able to be inferred, predicting behavior of change. In order to adopt this theory, behavior of changes, in intimacy, attitude, and behavior were used as theories. Measurement variables shown in considered for each construct used in this study were either selected or modified from previous studies.

\subsection{Intimacy}

Behavior-related research is based on the assumption of control of cognitive behavior and behavioural intention is determined behavioural intention [8]. On the other hand, there is a study of meta-analysis. It is likely to increase by individual action plan and motivation awareness [9-10]. According to Bandura (1977) [11], the decision to recognize behavioral control, the efficacy structure of self-confidence as an ability to perform an action. As well as study, which analyzes the relationship between physical exercise and behavioral intentions, has two effects on the 
attitude of intention [12]. Similar findings were reported [13-14]. There is a prior study of tourist intimacy. According to them, the speed of acquaintance is perceived by the experience of information exposure and advertisement [15], exposed to advertisements perceived by consumers, and the familiarity is perceived by the experience of information exposed by advertisement. In addition, experience and information that is said to have an impact on travelers is important in decision making [16]. According to Baloglu (2001) [17], the number of information combined with the experience directly affects the intimacy of tourists. In addition, the scope of evaluation of perception is closely related to intimacy [18] Therefore, it is very likely that intimacy will be attempted. This study attempted to adopt changing behavior as a basis for this. Foreign subjective experiences and attitudes as a factor in behavior of change

\subsection{Attitude}

The effect of attitude was composed that is a study of the effects of attitudes. according to Hagger, Chatzisarantis and Biddle (2002) [13], where attitudes, perceived control, and self-efficacy can be seen as intentions to change behavior. She described her will as an explanation of her attitude toward behavioral changes [19], attitudes were included as behavioral changes [20], it is appropriate to study social science by activating attitudes [21]. Therefore, it was composed of variables on a rational basis, which attempted to utilize attitudes as behavioral changes in Korean dance. With it, the attitude and visit experience of foreigners' intentions. A key issue in the intimacy and attitude of behaviour of change is that there is far from a perfect correlation between intentions, attitude and behaviour [22]. One approach that has been put forward to resolve the inadequacies of the behaviour of changing relationship in the intimacy, attitude, is "implementation intentions" [23]. These are goals and plans that involve specifying when, how, and where performance of behaviour of change will take place. It is said that the attitude of travelers develops as a rational behavior of change [24]. It is said to be crazy in cognitive psychology. Traveler attitudes directly affect behavioral changes [25]. In addition, studies have shown that it influences attitude. change as a subjective code of behavior [24], and perceived behavior of travelers affects cultural perception [26]. There is a study of travelers' attitudes [27]. Regarding consumer psychology and human behavior of change by advertisements such as tourism and rice products. When approaching the Korean dance on the intimacy, attitude, behavior of change of these travelers, there is a rather insufficient theoretical part. Nevertheless, the purpose of this study is to increase the objectivity of borrowing research and theory on the attitudes of travelers. Therefore, this study corrected and supplemented behavior of change and Korean dance creation to the attitude of travelers and utilized it theoretically.

\subsection{Changing Behavior}

Description of the theory with "Behavior of Change and Korean Dance Creation” (BCKDC), "BCKDC” is guided by five kinds of considerations: it was supported by the view of foreign visitors bout the likely consequences and experiences, information, watch behavior of change and Korean dance creation and path associated with behavior of change about it was supported by views due to the intimacy and attitude. In other to "BCKDC" to expectation and to consider it. Actually, surveyed for from the experience of foreign visitors to various channels. Assumed asked questions, experience of foreign decision makers, intimacy, attitudes [28], and information acquisition [29]. The family wanted to discover a significant existence. The existence of behaviour of changes and elements of Korean dance creation through proper control. made variables to increase the importance of research, objectivity of academic knowledge by proving the experience of foreign visitors. Also, to get results. How change behaviour is created and how can the difference be positive and negative. by studying the experiences of foreigners. It was the factor that applied is intimacy, attitude, experience, and information acquisition. Helped as an important result of the study, the impact of change behaviour and Korean dance creation can be expected. It was the need to strengthen behavioural change, and to mitigate behavioural change. It can be used as important for subsequent studies. To obtain the results has control variables, it was assumed, intimacy, attitude, experience, and information acquisition. It was the behaviour of change and the Korean dance curation.

\section{Methodology}

\subsection{Sample Data Collection}

The data was collected using a single self-report questionnaire that contained all the items used for measuring. Data used in this study were obtained from structured questionnaires designed to target those who were from 20 years to 80 years (under or over) and Interview Schedule. With at least high this is the basis for the sample material. Interview Schedule. We wanted to find out about foreigners who visited Korea, and the objectivity of behavioral change in Korean dance. It was applied as empirical data. The period of the visit was from October 12, 2014 to November 8. Informing and obtaining the research purpose, cooperation of sampling. It was supported by foreigners staying at L Hotel in Seoul, and by "J" travel agents. The target audience is 300 people from China, Japan, the United States, Europe and other 
countries. The language of the question is English, Chinese, and Japanese. It consisted of variables, the contents of "familiarity", "attitude" and "behavior" of Korean dance. Data was utilized, it was processed, 300 participants, 268 recalls, and unused, 32, and 268 final choices were adopted. Here are age-specific participants. Here are age-specific participants gender is male 146, and Female 122 . Here is by age. Age is under the 20years old, 29 peoples, from 20 to 40 years old is 144 peoples. from 40 to 60 years old is 6are 2 peoples, from 60 to 80 years old is 60 peoples and over 80 years old is 7 peoples. As well as Participants by country are shown. There are 84 Europeans, there are 45 American, there are 55 Japanese, there are 55 Japanese, there are 49 Chinse, and Other countries are 35 persons.

\subsection{Operation Variable}

The model's variables, intimacy based on were measured by the individual action plan and motivation awareness [9-10, 16-18] validated in a foreign visitor. It consists in 6 items answered in a Likert-type 4-point response scale. This questionnaire evaluates the six variables of (Closeness, Information, Characteristic Perception, Path of Diversity, Relevance, Communication and Attention). Intimacy: The familiarity variable is composed of explanations 1) The feeling of intimacy of the Korean dance 2) The information acquisition of the Korean dance makes an effort to hear information from the people around. 3) The characteristic of Korean dance is basic recognition. 4) The frequency of contact with the Korean dance acquisition route. 5) The intelligence of the Korean dance is the transmission of information. Perceived control, and self-efficacy and implementation intentions can be seen as intentions to change behavior. She described her will as an explanation of her attitude by the Chatzisarantis and Biddle (2002) [12], Armitage (2005) [19], Mohiydini, Pauli and Bauer (2009) [20], Nigg, Lippke and Maddock (2009) [21], Biddle and Fuchs (2009) [22]. Attitude was measured using 5 items that included. The sentence preceding the adjectives was "(Attention, Freshness Attractive, Interesting, and Usefulness) would be attitude consistency of the subscale was it. Attitude: Korean dance attitude variables were composed. 1) Interest in watching performances on Korean dance. 2) A sense of divinity with the mystique of Korean dance. 3) Watching Korean dance is fascinating. 4) The usefulness of Korean dance is beneficial to you. 5) I am interested in Korean dance. behavior of change: was evaluated using 6 items which were answered on a scale of completely disagree to 5 points completely agree. according to Willock, etc. (1999) [6], Barney and Griffin, (1992) [7]. behavior of change was measured suing (Expectation, Active, National, Acceptability, Relation and variation). in this way is seen as an objective and inter- subjectivity in the life world includes the meaning of accumulated time knowledge to understand [30]. therefore, changing behavior has a theoretical implication that can explain. behavior of change: variables were constructed [31]. 1) The behavior of change and Korean dance creation is the expectation of the schedule of visits. 2) The behavior of change and Korean dance creation is active to see again. 3) Continuity of interest in the behavior of change and Korean dance creation. 4) The behavior of change and Korean dance creation is acceptability. 5) Intimacy by experience of the behavior of change and Korean dance creation. 6) The behavior of change and Korean dance creation is the diversity of cultural and artistic understanding [32].

\subsection{Research Model}

The structure of the proposed framework is shown in $<$ Figure 1> In total, 3 independence variables are drawn from constructs of 3 independent variables, 16 of which included 6 as each sub-variable. It consisted of 2 intervening variables, 11 of which including 2 as each sub variable. It consists of behavioral changes. The dependent variable consists of six factors. It was the sub-variables of behavior change were composed, which is intimacy, attitude, and changing behaviour towards overview form. study on the Change of Korean Dance Behavior Comparison intention for Korean dance develops and promotes.

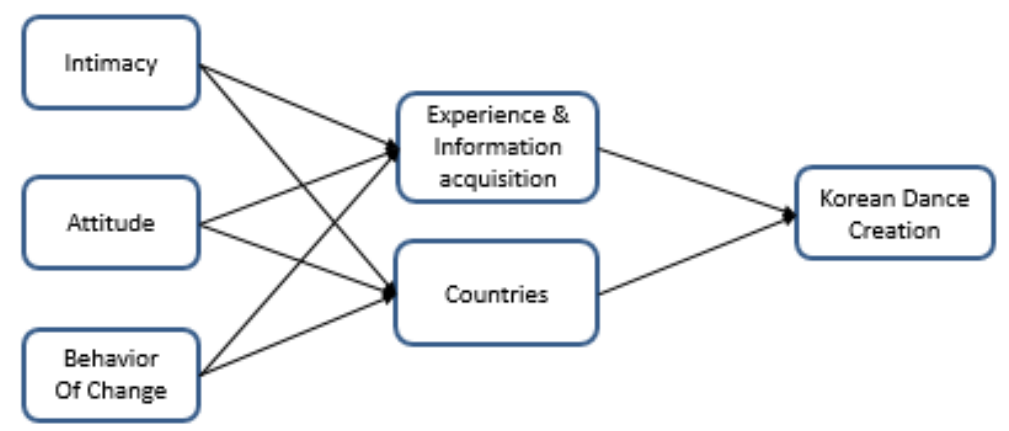

Figure Research model 1

Figure 1. Independence variables are drawn from constructs of 3 intimacy, attitude and behaver of change as; intervening variables are countries and experience \& information acquisition; the dependent variable consists of Korean dance creation 
In probability, both kind of definition are used "T" what is T1, T2, and T3 tossing three, and are used "P" what is P1, P2 listed all the possible "P" rule definition. In case of ' $\mathrm{T}$ " is product first $\mathrm{T} 1, \mathrm{~T} 2$, and $\mathrm{T} 3$ independent variable. Second product of two set is the all of intervening variable enter of another set. Third product of one set is "N" and "O" dependent variable enter of the set. It can $<$ Figure 1> generation of the product of this case. this study used the number of possible outcomes, with three " $\mathrm{T}$ " first set and "P" second set product can be used "N" and "O", in defining sample space actual.

\subsection{Research Direction}

This study was operation variables in accordance with the principles for conducting research with foreign visitor participants, and completion of the study questionnaire by participants was taken to indicate their informed consent. It was composed of independent variables It consisted of independent variables, which were intimacy, attitudes, experiences and acceptance relationships for information acquisition. Characteristic Perception of Korean dance, Path of Diversity of Korean dance, Relevance of intimacy, attitude, attention performance, attractive, and usefulness. Expectations of the behaviour of change, which were attitudes of behavior, intimacy, acceptance, and relationships. Intervening variable was composed of country-by-country and visitor experiences and cultural pathways, and dependent variable Korean dance creation, and it has two sub-variables. It is becoming the visit experience and visit route. By being refined, Korean culture develops with intimacy in the world. Total of six constructs were used. towards green products was measured on six items and extracted from previous studies, familiarity variable is composed of explanations. 1) The feeling of intimacy of the Korean dance creation. 2) The information acquisition of the Korean dance creation makes an effort to hear information from the people around. 3) The characteristic of Korean dance creation is basic recognition. 4) The frequency of contact with the Korean dance creation acquisition route. 5) The intelligence of the Korean dance creation is the transmission of information. Stoned, perceived behavioural control was measured on four items based on countries and overview form, Korean dance creation concern was measured by five different items, as proposed dependence variables.

\subsection{Tools Analysis}

Data analyses were conducted using the statistical package for social sciences (SPSS 21) and analysis of moment structures (regression) software, to achieve the purpose and to test analysis of this study. SPSS 21.0 was used for descriptive analysis to analyse preliminary results and to find out the demographic characteristics of the sample. For a more detailed review, with frequency, factor analysis regression was used to assess the adequacy of measurement for confirming the reliability, convergent and divergent validity, followed by using change of behaviour to test the study constructs. secondary analysis of data was extracted from "behavior of change and Korean Dance creation” (CBKDC).

\subsection{Statistical Analysis}

In statistics related to intimacy, attitudes, and behaviour of change. It sees the difference in the behavioral of change and Korean dance creation by the experiences, expectations, and paths of participants by country. In relation to this, the impact on behavioral of change by country is indicated by statistics from regression analysis. General participation statistics are explained by frequency analysis. In order to investigate the effects of intimacy, attitudes, and changing behaviour on intention, In accordance with three latent variables were specified in order to prove their validity as a causal model: intimacy (6 items), attitude (5 items), behaviour of change (6 items) and others from the view (2 items) and National (3 items). It was assumed. 1) independent variables do the same, 2) Frequency analysis has a normal distribution, 3) Factor analysis captures each variable factor, and 4) Regression analysis assumes the influence of dependent variables. As a result of the analysis, it was important to increase the objective knowledge of individual variables.

To help clearly understand to set up the equation of "define" each variable that as it is below.

a). Dependent Variable: “ $\mathrm{T}$ " = T1 (intimacy), $\mathrm{T} 2$ (attitude), T3 (behaviour of change)

b). Dependent Variable: "P" = P1 (visit experience), P2 (approach path)

c). Dependent Variable: “N" = T1 (intimacy, $\mathrm{T} 2$ (attitude), T3 (behaviour of change, Nationality)

d). Dependent Variable: "O" = Korean Dance Creation: “T”+" P" + "N"

The result agrees with our previous sample reasoning, if we make the problem a bit more complex. However, maybe the formula will be more useful. In the general case output result was nationality. The results were as follows, Europe, was 31.3 (\%), America was 6.8 (\%), Japan was 20.5 (\%), China was 18.3 (\%), and Others was 13.1 (\%). The analysis results can be summarized and explained. Euro was more interesting conditional probability them China, Japan, and others countries. The details of the variable are shown.

Factors analysis assumed a good reason for including both of them in our little test bbattery, after test are administered and scored, coefficients of correlation are calculated between each test and every other test. That matrix is ant rectangular array of numbers. Correlation matrices are always square and symmetric. This case is easy to answer there are two factors indicate by the two clusters of raw circled and labelled. There are conceived 
to be different of related ways intimacy, attitude and behaviour of change and Korean dance creation can influence. this study designed a questionnaire by several measure 3 modes of the behaviour of change and foreign visitors experience to contribute factors of these measurement that question administered to the variable sample. Therefor require factor analysis relation between highly abstract and constructs or latent variables.

Table 1. Frequency Analysis

\begin{tabular}{|c|c|c|c|}
\hline \multicolumn{2}{|c|}{ Division } & $\begin{array}{c}\text { Frequency } \\
\text { Person } \\
\end{array}$ & $\begin{array}{c}\text { Valid } \\
\text { Percent }\end{array}$ \\
\hline \multirow{5}{*}{ Nationality } & Europe & 84 Persons & $31.3(\%)$ \\
\hline & America & 45 Persons & $16.8(\%)$ \\
\hline & Japan & 55 Persons & $20.5(\%)$ \\
\hline & China & 49 Persons & $18.3(\%)$ \\
\hline & others & 35 Persons & $13.1(\%)$ \\
\hline \multicolumn{2}{|r|}{ Total } & 268 Persons & $100(\%)$ \\
\hline \multirow{2}{*}{ Sex } & Male & 146 Persons & $54.5(\%)$ \\
\hline & Female & 122 Persons & $45.5(\%)$ \\
\hline \multicolumn{2}{|r|}{ Total } & 268 Persons & $100(\%)$ \\
\hline \multirow{5}{*}{ Age } & under the age of 20 & 29 Persons & $10.8(\%)$ \\
\hline & 20 to under 40 years & 144 Persons & $53.7(\%)$ \\
\hline & 40 to under 60 years & 62 Persons & 23.1(\%) \\
\hline & 60 to under 80 years & 26 Persons & $9.7(\%)$ \\
\hline & over 80 years & 7 Persons & $2.6(\%)$ \\
\hline \multicolumn{2}{|r|}{ Total } & 268 Persons & $100(\%)$ \\
\hline
\end{tabular}

(*SPSS, Result)

Factors independent of each other are irrelevant. The program was applied with varimax. The information about the factor is not accurate, so it is proved in a way to prove the existing relationship. It is Principal component analysis. component analysis, Rotation method, Varimax with Kaiser normalization. Factors analysis is an exploratory data analysis or latent variables from set of observed variables.it help in date interpretation by reducing the number of variables. Assuming factors analysis is applied 1) sample size should be great then the factor 2) should not be perfect multicollinearity 3) should not be homoscedasticity between the variables. Therefore, each variable constituted factor redemption.

As a result of agglomeration, the basic factors were aggregated and the variables were aggregated, resulting in a factor of 0.5 or higher, which is expressed. First, it can be interpreted as having probability. It was indicated, 0.5 $<0.764,0.5<0.561,0.5<0.725,0.5<0.871,0.5<0.723$, and $0.5<0.713$ respectively. Therefore, it is used as a variable, and intimacy has statistical validity. Second, it has a strong connection. It is expressed as a variable standard for attitude. It increases the likelihood. It is displayed. The values of the variables are $0.5<0.665$, 0.5 $<0.648,0.5<0.792,0.5<0.852$, and $0.5<0.763$. These values have statistical significance as explanatory variables. Third, increase the variable explanation of the behavior of change of foreign visitors. Third, it enhances the cohesion of variable explanation. It shows $0.5<0.631$, $0.5<0.729,0.5<0.744,0.5<0.637,0.5<0.669$, and 0.5 $<0.853$ by indicators. The details of the variable $<$ Table-2-> are shown. The above explanatory indicators were the basis for increasing the cohesiveness of the factors. In this study, intimacy, attitude, and the behaviour of change were factor variables. The results of these analyzes generally exceed 0.5 , and when the average shows the results of the analysis, it can be explained that this study is highly regarded as a factor that can be used as the behaviour of change factor for Korean dance creation products.

Table 2. Factor Analysis

\begin{tabular}{|c|c|c|c|}
\hline Indicator & Cohesion of variable & Factor1 & Factor2 \\
\hline \multirow{6}{*}{ Intimacy } & $\begin{array}{l}\text { Closeness of the Korean } \\
\text { dance creation }\end{array}$ & .648 & .764 \\
\hline & $\begin{array}{l}\text { Information of the Korean } \\
\text { dance creation }\end{array}$ & .520 & .561 \\
\hline & $\begin{array}{l}\text { Characteristic Perception of } \\
\text { Korean dance creation }\end{array}$ & .688 & .725 \\
\hline & $\begin{array}{l}\text { Path of Diversity of the } \\
\text { Korean dance creation }\end{array}$ & .844 & .871 \\
\hline & $\begin{array}{l}\text { Relevance of the Korean } \\
\text { dance creation }\end{array}$ & .605 & .723 \\
\hline & $\begin{array}{l}\text { Communication of the Korean } \\
\text { dance creation }\end{array}$ & .596 & .713 \\
\hline \multirow{5}{*}{ Attitude } & $\begin{array}{l}\text { Attention of the Korean dance } \\
\text { creation }\end{array}$ & .557 & .665 \\
\hline & $\begin{array}{l}\text { Freshness of the Korean dance } \\
\text { creation }\end{array}$ & .557 & .648 \\
\hline & $\begin{array}{l}\text { Attraction of the Korean } \\
\text { dance creation }\end{array}$ & .767 & .792 \\
\hline & $\begin{array}{l}\text { Interesting of the Korean } \\
\text { dance creation }\end{array}$ & .860 & .852 \\
\hline & $\begin{array}{l}\text { Usefulness of the Korean } \\
\text { dance creation }\end{array}$ & .764 & .763 \\
\hline \multirow{6}{*}{$\begin{array}{l}\text { Changing } \\
\text { Behavior }\end{array}$} & $\begin{array}{l}\text { Expectations of the behavior } \\
\text { of change }\end{array}$ & .580 & .631 \\
\hline & $\begin{array}{l}\text { Active of the behavior of } \\
\text { change }\end{array}$ & .746 & .729 \\
\hline & $\begin{array}{l}\text { National of the behavior of } \\
\text { change }\end{array}$ & .744 & .744 \\
\hline & $\begin{array}{l}\text { Acceptability of the behavior } \\
\text { of change }\end{array}$ & .576 & .637 \\
\hline & $\begin{array}{l}\text { Relation of the behavior of } \\
\text { change }\end{array}$ & .609 & .669 \\
\hline & Variation of change behavior & .823 & .853 \\
\hline
\end{tabular}

*Principal Component Analysis. Rotation Method: Varimax with Kaiser Normalization 
Table 3. Regression Analysis

\begin{tabular}{|c|c|c|c|c|c|c|c|c|}
\hline \multirow[b]{2}{*}{ Model } & \multirow{2}{*}{$\begin{array}{c}\mathbf{R} \\
\text { Square }\end{array}$} & \multirow{2}{*}{$\begin{array}{l}\text { Adjusted } \\
\text { R Square }\end{array}$} & \multirow{2}{*}{$\begin{array}{c}\text { Standardized } \\
\text { Coefficients } \\
\text { Beta }\end{array}$} & \multicolumn{5}{|c|}{ Change Statistics } \\
\hline & & & & $\begin{array}{c}\text { R square } \\
\text { Change }\end{array}$ & $\mathbf{F}$ & Df1 & Df2 & $\begin{array}{c}\text { Sig F } \\
\text { change }\end{array}$ \\
\hline T3: Behavior of change & 1.083 & .315 & 3.698 & $0.95-$ & 9.195 & 3 & 264 & .001 \\
\hline Tl: Intimacy & .095 & 195 & .033 & .215 & 9.195 & 3 & 264 & .000 \\
\hline T2: Attitude & .193 & .168 & .106 & .264 & .5 .270 & 17 & 250 & .000 \\
\hline P1: Visiting purpose & 0.76 & .055 & 1.379 & .064 & 3.58 & 6 & 261 & .002 \\
\hline P2: Nationality & .047 & .043 & .943 & .047 & 13.069 & 1 & 256 & .000 \\
\hline $\begin{array}{l}\text { “O”: Korea dnace } \\
\text { creation }\end{array}$ & .686 & .681 & .544 & .684 & 143.419 & 4 & 263 & .000 \\
\hline
\end{tabular}

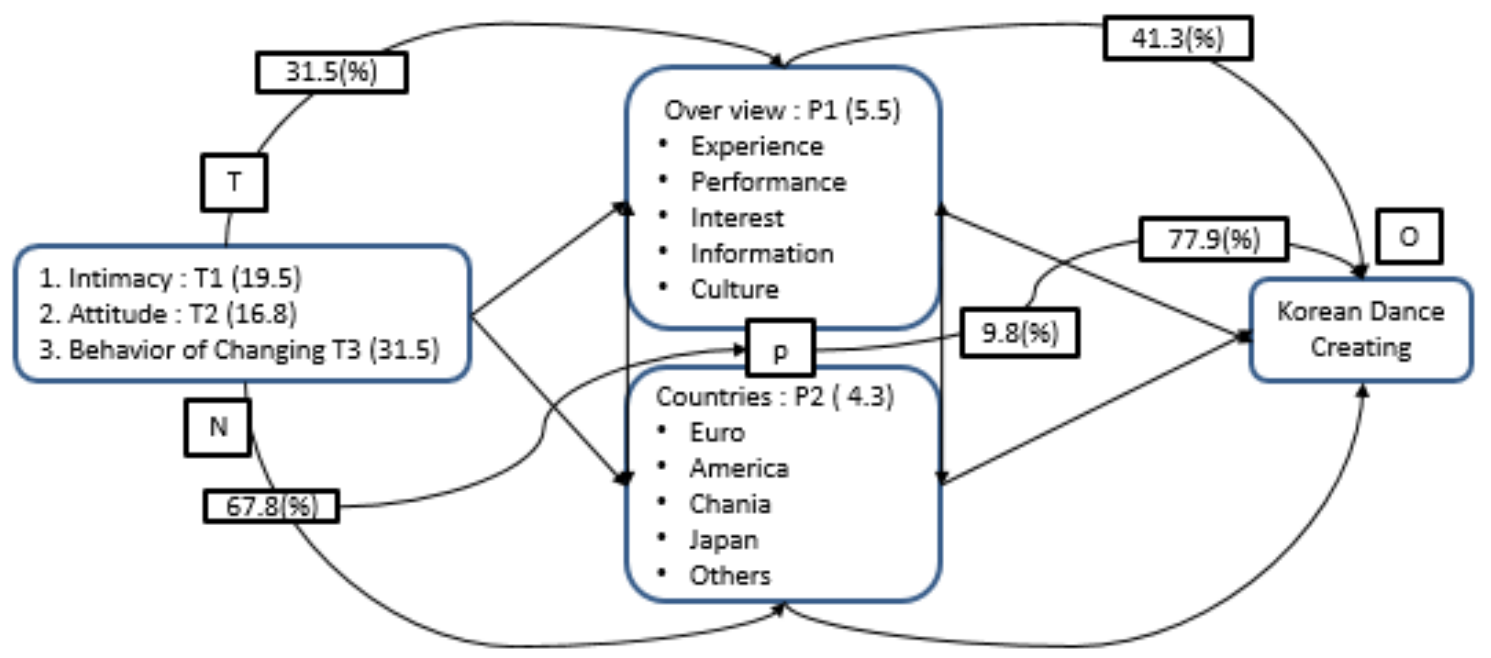

Figure 2. Regression Analysis

Regression analysis supported the degree of impact Definition are used first: "T" what is T1, T2, and T3 tossing three, in case of ' $\mathrm{T}$ " is product first $\mathrm{T} 1, \mathrm{~T} 2$, and $\mathrm{T} 3$ independent variable. Second product of two set is the all of intervening variable enter of another set. and are used "P" what is P1, P2 listed all the possible "P" rule definition. Third, product of two set is the all of intervening variable enter of another set. Third product of one set is "N" toward changing behaviour and "O" dependent variable enter of the set. and enter of Korean dance create

Figure 2. The regression analysis was explained are explained, which were intimacy 19.5(\%), attitude 16.8(\%), and behavior of change 31.5(\%), and which were countries 4.4(\%), and experience \& information acquisition 5.5(\%), and Comprehensive variables on the Korean dance creation of dependent variables show $77.9(\%)$ impact.

It was that the results of the structural model, and the standardized path coefficient indicated positive effects among the constructs in the structural model. In total were supported. The result of regression was $p<0.001$ ) indicated that the behaviour of change was supported. According to Be the positive estimate of coefficients between. It showed the ability to explain intimacy 19.5(\%), and attitude 16.8 (\%), intention for Changing 31.5(\%), had significant positive effects $p<0.001$ ). thus, was supported. The impact of perceived the behaviour of change control Adjusted R Square total 67.8(\%), $p<0.001$ ) had significant positive effects on change behaviour supporting.

"P1" "P2" It showed the to explain visiting purpose was 5.5(\%), and Countries was 4.3(\%), the impact of deceived of the behaviour of change, $\mathrm{R}^{2}$ 9.8(\%), $p<0.002$ ) had significant positive effects on the behaviour of change, response. Nationality showed significant positive influences on intimacy and attitude towards the behaviour of change, products, which is "Nationality" T1: 19.5(\%), T2: 16.8(\%), T3: 31.5(\%), toward " $\mathrm{N}$ " was $67.8(\%)$. However, it had indirect effects through intimacy and attitude towards the behaviour of change product. Assuming Korean Dance creation was support, "T" intimacy, attitude, and behaviour of change, (T1, T2, T3), "P" foreign experience, information path (P1, P2), and "N" the behaviour of change, $(\mathrm{N})$ and toward Korean dance creation (O) had significant positive responded.

" $T$ " was support. the positive estimate of between nationality and Intimacy, attitude for changing behaviour products had significant positive effects 67.8(\%), (T1+T2+T3). "P" was support. The impact of experience and approach path for the behaviour of change, changing 
behaviour products had significant positive effects $9.8(\%)$, (P1+P2). Intimacy and attitude concern had significant positive effect on $68.1(\%)$, the behaviour of change, and towards Korean dance creation effect on and visit purpose and the behaviour of change, 77.9(\%).

Finally, environmental knowledge showed significant positive influence on intimacy, attitude toward the behaviour of change, products $67.8(\%)$, and as well as experience and approach path effects on $9.8(\%)$, and the behaviour of change effects on): 68.1(\%), thus supporting "T1", "T2", "T3", and "P1", "P2" and "N" and "O" towards Korean dance creation "O". However, environment knowledge showed insufficient impact significant influence on performance time. Hence it had indirect effects through intimacy, attitude towards the behaviour of change products, Korean dance creation.

The results of this study include, lack of discourse and academic and theoretical instability [33]. I would like to finish with a suggestion. The necessity of detailed follow-up studies to overcome the theoretical limit between the sports of traditional dance and the interdisciplinary sociology [34].

\section{Author Contributions}

For research articles with several authors, a short paragraph specifying their individual contributions must be provided. The following statements should be used "Conceptualization, J.Y, Yoo, and methodology, Y. S, Kim; software, J.Y, Yoo; validation, Y. S, Kim and formal analysis, Y. S, Kim; investigation, J. Y, Yoo; resources; data curation, J.Y, Yoo; writing — original draft preparation, J.Y, Yoo; writing-review and editing, Y. S, Kim; visualization; supervision, Y. S, Kim; project administration, Y. S, Kim; funding acquisition, Y. S, Kim. All authors have read and agreed to the published version of the manuscript.", please turn to the Credit taxonomy for the term explanation. Authorship must be limited to those who have contributed substantially to the work reported. Yeon Soo, Kim

\section{REFERENCES}

[1] Jung, B. H. (1999). Traditional dance of Korea. Jipmoondang: Seoul, 1-926.

[2] Yoo, J. Y., \& Kim, M. K. (2019). Convergence of Korean traditional dance and K-Pop dance: An analysis of comments on 2018 MMA BTS 'IDOL' videos on YouTube. Journal of Korea Entertainment Industry Association, 13(8), 189-198. https://doi.org/10.21184/jkeia.2019.12.13.8.189

[3] Willock, J., Deary, L. J., McGregor, M. M., Sutherland, A., Jones, G. E., Morgan, O., Dent, B., Grieve, R., Gibson, G., \& Austin, E. (1999). Farmers' attitudes, objectives, behaviors, and personality traits: The Edinburgh study of decision making on farms. Journal of Vocational Behavior, 54(1), 5-36. https://doi.org/10.1006/jvbe.1998.1642

[4] Barney, J. B., \& Griffin, R. W. (1992). The management of organizations: Strategy, structure, behavior. Houghton Mifflin CO: Boston, MA.

[5] Kim, Y. S., \& Michael May. (2013). A comparative study of the energy policy making od the South Korea \& Germany: With focused on to hermeneutics Methodology. Korea Comparative Government Review, 17(1), 95-124.

[6] Kim, Y. S., \& Lee, S.Y. (2013). A study of stakeholder behavioral appearance process for unification of Germany: with focused on phenomenological methodology. Korean Comparative Government Review, 17(2), 49-72.

[7] Kim, H. M., \& Kim Y. S. (2012). Über die Besonderheiten des Parsings in verschiedenen linguistischen Theorien. Language \& Information Society, 18(1), 149-165.

[8] Ajzen, I. (1991). The theory of planned behavior. Organizational Behavior and Human Decision Processes, 50(2), 179-211.

[9] Randall, D. M., \& Wolff, J. A. (1994). The time interval in the intention - behavior relationship: Meta - analysis. British Journal of Social Psychology, 33(4), 405-418. https://doi.org/10.1111/j.2044-8309.1994.tb01037.x

[10] Sheppard, B. H., Hartwick, J., \& Warshaw, P. R. (1988). The theory of reasoned action: A meta-analysis of past research with recommendations for modifications and future research. Journal of Consumer Research, 15(3), 325-343. https://doi.org/10.1086/209170

[11] Bandura, A. (1977). Self-efficacy: Toward a unifying theory of behavioral change. Psychological Review, 84(2), 191-215. https://doi.org/10.1037/0033-295X.84.2.191

[12] Hausenblas, H. A., Carron, A.V., \& Mack, D. E. (1997). Application of the theories of reasoned action and planned behavior to physical activity behavior: A metanalysis. Journal of Sport and Physical Activity Psychology, 19, 35-51.

[13] Hagger, M. S., Chatzisarantis, N. L. D., \& Biddl, S. J. H. (2002). A meta-analytic review of the theories of reasoned action and planned behavior in physical activity: Predictive validity and the contribution of additional variables. Journal of Sport \& Exercise Psychology, 24, 3-32.

[14] Jackson, C., Smith, A., \& Conner, M. (2003). Applying an extended version of the Theory of Planned Behavior to physical activity. Journal of Sports Sciences, 21(2), 119-133. https://doi.org/10.1080/0264041031000070976

[15] Alba, J. W., \& Hutchinson, J. W. (1987). Dimensions of consumer expertise. Journal of Consumer Research, 13(4), 411-454. https://doi.org/10.1086/209080

[16] Kim, H., \& Richardson, S. L. (2003). Motion picture impacts on destination images. Annals of Tourism Research, 30(1), 216-237. https://doi.org/10.1016/S0160-7383(02)00062-2

[17] Baloglu, S. (2001). Image variation of Turkey by familiarity index: Informational and experiential dimensions. Tourism Management, 22, 127-133.

[18] Mackay, K. J., \& Fesenmaier, D. R. (1997). Pictorial 
element of destination in image formation. Annals of Tourism Research, 24(3), 537-565. https://doi.org/10.1016/S0160-7383(97)00011-X

[19] Armitage, C. J. (2005). Can the theory of planned behavior predict the maintenance of physical activity? Health Psychology, 24(3), 235-245. https://doi.org/10.1037/0278-6 133.24.3.235

[20] Mohiyeddini, C., Pauli, R., \& Bauer, S. (2009). The role of emotion in bridging the intention-behavior gap: The case of sports participation. Psychology of Sport and Exercise, 10(2), https://doi.org/10.1016/j.psychsport.2008.08.005

[21] Nigg, C. R., Lippke, S., \& Maddock, J. E. (2009). Factorial invariance of the theory of planned behavior applied to physical activity across gender, age, and ethnic groups. Psychology of Sport and Exercise, 10(2), 219-225. https://doi.org/10.1016/j.psychsport.2008.09.005

[22] Biddle, S. J. H., \& Fuchs, R. (2009). Exercise psychology: A view from Europe. Psychology of Sport and Exercise, 10(4), 410-419. https://doi.org/10.1016/j.psychsport.2009.02.011

[23] Gollwitzer, P. M., \& Sheeran, P. (2006). Implementation intentions and goal achievement: A meta - analysis of effects and processes. Advances in Experimental Social Psychology, 38, 69-119. https://doi.org/10.1016/S0065-260 1(06)38002-1

[24] Fishbein, M., \& Ajzen, I. (1975). Belief, attitude, intention and behavior: An introduction to theory and research. Reading, MA. Addison-Wesley: Boston, 1-578.

[25] Maichum, K., Parichatnon, S., \& Peng, K. C. (2016). Application of the extended theory of planned behavior model to investigate purchase intention of green products among. Sustainability, 8(10), 1-20.https://doi.org/10.3390/s u8101077
[26] Doll, J., \& Ajzen, I. (1992). Accessibility and stability of predictors in the theory of planned behavior. Journal of Personality and Social Psychology, 63(5), 754-765. https://doi.org/10.1037/0022-3514.63.5.754

[27] Fishbin, M., \& Ajzen, I. (1975). Belief, attribute, international and behavior: An introduction to theory and research, MA; Addison Wesley.

[28] Fornell, C, \& Johnson, M. D. (1992). A national customer satisfaction barometer: The Swedish experience. Journal of Marketing, 56(1), 6-21.

[29] Kim, Y. S. (2020). The study on the social science methodology: Focusing on change in the behavior of Policymakers. Technium Social Sciences Journal, 6(1), $1-17$.

[30] Oliver, R. L. (1980). A cognitive model of the antecedents and consequences of satisfaction decisions. Journal of Marketing Research, 17(4), 460-469. https://doi.org/10.117 7/002224378001700405

[31] Boulding, W., Kalar A., Staelin, R., \& Zeithamal, V.A. (1993). A dynamic model of consumer assessment of service quality and value. Journal of Consumer Research, 17(4), 375-384.

[32] Jones, T. O., \& Sasser, W. E. (1995). Why satisfied customer defect. Harvard Business Review, 73(6), 88-99.

[33] Japhet Ndayisenga., \& Tomoliyus. (2019). Effect of service quality and rates on satisfaction and loyalty of customer behavior at fitness. International Journal of Human Movement and Sports Sciences, 7(2), 25-32. https://doi.org/10.13189/saj.2019.070202

[34] Yoo, J. Y. (2013). An exploration on the possibility of developing Korean Taekwonmu. Journal of Korean Dance, 31(3), 247-270. 